\title{
Study on the Personal Credit Risk Evaluation based on Improved Fuzzy AHP Comprehensive Evaluation Method
}

\author{
Yan $\mathrm{Li}^{1, \mathrm{a}}$ \\ ${ }^{1}$ Guilin University of Electronic Technology, Guilin, Guangxi, China, 541004 \\ ${ }^{a}$ email
}

\begin{abstract}
Keywords: Personal Credit; Fuzzy Comprehensive Evaluation; Delphi; Interpolation; Group Decision Making AHP
\end{abstract}

\begin{abstract}
On the basis of personal credit rating methodology from home and abroad, combined with the current status of financial institutions, credit rating and specific operational measures, proposed using Modified Fuzzy comprehensive evaluation of individual credit assessment. The method utilizes AHP and group decision making Delphi the right to determine the Combination of the evaluation indexes, obtained quantitative indicators and qualitative indicators set membership for comment were using expert grading method and interpolation, the final overall score by calculating the fuzzy credit risk of individual scientific and reasonable evaluation.
\end{abstract}

\section{Introduction}

Personal credit rating of various financial institutions and credit evaluation system is very important part. In recent years, with the rapid development of China's city commercial banks, rural banks, small loan companies and other business loans of financial institutions, the credit business on individual credit risk assessment more and more attention these financial institutions. Domestic and foreign scholars on individual credit risk rating mainly to the selection and establishment of evaluation index system model. The paper, on the basis of the existing theory, proposed to use fuzzy comprehensive rating method and AHP binding to individual credit evaluation. Improvement of basic principles of Fuzzy AHP Comprehensive Evaluation Method is: fuzzy comprehensive evaluation method is based on many factors affect individual credit risk analysis and classification, a multi-level factor set; binding as any other individual financial institutions, credit rating, determined reviews various indicators set; the right AHP group decision Making and Delphi combination determine index weight; using expert grading method and interpolation method to get the membership of each metric comment sets; finally re-allocated according to weight index is calculated comprehensive evaluation vector obtained personal credit evaluation of the final score.

\section{Improve a Specific Level Fuzzy Comprehensive Evaluation Method in the Personal Credit Evaluation Process}

Establish A Personal Credit Evaluation Factors Set. Individual credit risk assessment to determine the factors set individual credit risk assessment is carried out during the most crucial step, it directly

Determine the accuracy of the credit evaluation results. Individual credit risk rating index system in the detailed analysis and comparison of many financial institutions used, based on the research results of other scholars presented in the table shown in the individual credit risk rating index system. 
Table 1 individual credit risk assessment system table

\begin{tabular}{|c|c|c|}
\hline $\begin{array}{c}\text { Level } \\
\text { indicators }\end{array}$ & Secondary indicators & Rating Standard Description \\
\hline \multirow{5}{*}{$\begin{array}{c}\text { base } \\
\text { this } \\
\text { situation } \\
\text { condition }\end{array}$} & age & The young higher score, other lower \\
\hline & marital status & Married score of 1 , single score of 0 \\
\hline & Local residence & The longer the residence time, the higher the score \\
\hline & education level & The higher level of education, the higher the score \\
\hline & employer & $\begin{array}{c}\text { National enterprises, public institutions, civil servants, } \\
\text { teachers score higher }\end{array}$ \\
\hline \multirow{4}{*}{$\begin{array}{c}\text { Family } \\
\text { court } \\
\text { fiscal } \\
\text { Business }\end{array}$} & Fixed assets & Other fixed assets appraised value of real estate, cars, etc. \\
\hline & Current assets & Total current assets of bank deposits, securities, etc. \\
\hline & $\begin{array}{l}\text { Total annual } \\
\text { expenditure }\end{array}$ & Total household consumption expenditure \\
\hline & Total annual revenue & The total annual income of family members \\
\hline \multirow{3}{*}{$\begin{array}{c}\text { letter } \\
\text { loan } \\
\text { shape } \\
\text { condition }\end{array}$} & Bank credit balances & Is there a bank credit, and balance of payments is not \\
\hline & Hostage situation & Provide collateral valuation price \\
\hline & Guarantees & $\begin{array}{l}\text { Whether to provide guarantees, and the amount of } \\
\text { collateral }\end{array}$ \\
\hline \multirow{3}{*}{$\begin{array}{l}\text { letter } \\
\text { use } \\
\text { Row } \\
\text { for }\end{array}$} & Bank credit record & $\begin{array}{l}\text { Whether the use of credit cards and bank loans have a bad } \\
\text { record, that the amount of arrears }\end{array}$ \\
\hline & $\begin{array}{l}\text { Non-payment of tax } \\
\text { records }\end{array}$ & $\begin{array}{l}\text { Non-payment of taxes, utilities, telephone number and the } \\
\text { amount of fees }\end{array}$ \\
\hline & $\begin{array}{l}\text { Law and discipline } \\
\text { cases }\end{array}$ & Gambling, drug abuse and other violations of the law \\
\hline
\end{tabular}

The evaluation index system draws on analysis of other financial institutions, credit rating personal situation, through the basic situation and credit status related to family finances, credit and credit behavior of four-level indicators. For a more comprehensive collection of personal credit information, at every level indicators is subdivided into a plurality of secondary indicators, qualitative assessment and quantitative analysis of a combination of personal credit situation to make more accurate and comprehensive evaluation.

Determine the Set of Reviews. Binding definition of other commercial banks and credit rating agencies to individual credit ratings, the establishment of evaluation set five personal credit final assessment results with " $U$ " to represent, the comment set $U=\left(U_{1}, U_{2}, U_{3}, U_{4}, U_{5}\right)$, respectively (excellent, good, fair, poor, very poor) five levels, corresponding to the results of individual credit risk assessment is low, low, in general, higher, higher.

Determine the Index Weight. In this paper, the use of Group Decision Analytic Hierarchy Process (AHP) and Delphi Combination of individual credit risk assessment to determine the weight of the index weight. Table 1 shows that individual credit risk evaluation factors were four level indicators and secondary indicators composed of fifteen. Four-level indicators corresponding weight set respectively $\mathrm{W}=\left(W_{1}, W_{2}, W_{3}, W_{4}\right)$, two indicators $U_{i j}$ with respect to the right to an index $U_{i}$ of weight $U_{i j}$. Weight determination Expert Group to ensure that strangers among individual experts engaged by the right credit evaluation index credit evaluation research scholars, 
the CBRC management, bank loan officers, credit rating agencies, and many staff composition. Respectively to each of the group issuing personal credit evaluation importance of the questionnaire, after repeated projections, discussions, research and study, get all the expert judgment of each matrix index attributes. Obtained feature vector $\mathrm{W}$ i-th component using the geometric mean method.

$$
W_{\mathrm{i}}=\left(\prod_{j=1}^{n} \beta_{\mathrm{ij}}\right)^{\frac{1}{n}}
$$

Then each component $\left(W_{1}, W_{2}, W_{3}, W_{4}\right)$ were normalized to give $U_{i}$ a $U$ about the relative importance of the vector $W_{i}$. Similarly, an index can be calculated under the two respective $U_{i j}$ index weight $\mathrm{W}$, and ultimately get the right weight for all indicators set $\mathrm{W}$.

$$
W_{\mathrm{i}}=\frac{\bar{W}_{\mathrm{i}}}{\sum_{\mathrm{i}}^{n} \bar{W}_{i}}
$$

Determine Index Membership for Comment and Fuzzy Judgment Matrix. Table 1 shows the individual credit risk assessment system, including the evaluation of quantitative indicators numerically and in words

Expression level of qualitative indicators and quantitative indicators in accordance with different values is divided into discrete and continuous variables, when the score for these different types of indicators need to use different methods to determine its membership. Constituted by the fuzzy membership matrix $\mathrm{R}$. rating

Qualitative indicators can be divided into two types, one is the use of quantitative methods grade rating indicators, such as: education, work units, law and discipline cases, these indicators need expert scoring method, according to the actual situation was evaluators determine its membership: excellent 1-0.8 points, good 0.8-0.6 points in the 0.6 to 0.4 points, the difference between $0.4-0.2$ points, very poor $0.2-0$ points. First by a plurality of experts are given for each indicator membership of reviews score, and then score each of the indicators in each of the reviews were average, as the value of its final membership. Another choice is a binary variable indicators such as: marital status, married score higher index is "1", a single low score "0."

Quantitative indicators use interpolation to map the actual value of the indicator on the corresponding $[0,1]$. Credit raters by actual survey of personal income and credit situation in the region, the optimal value and the worst value of the personal credit evaluation, and the optimal value is set to "1", the worst value is set to " 0 " establishment of index values interval [0, 1$]$, respectively, and then map the actual evaluation of the data to the corresponding $[0,1]$ to obtain membership of the indicators of the actual value. Since the indicators are positive and reverse of the points, the higher the score positive indicators, such as: fixed assets, current assets, total annual income, collateral, the guarantees and other indicators, the customer's credit rating, the higher the score; reverse indicator the higher the score, such as: total annual spending, the balance of bank credit, bank credit, non-payment of tax records and other indicators, the customer's credit rating, the lower the score. Therefore, when different types of index calculation membership should use different formulas:

For positive indicators: $R(\mathbf{i})=\frac{x-x_{i}}{x_{i+1}-x_{i}}$

For reverse indicators: $\mathrm{R}(\mathrm{i})=\frac{x_{i+1}-x}{x_{i+1}-x_{i}}$

Among them, the limits $x_{i}, x_{i+1}$ are different evaluation score range $x_{i}<x<x_{i+1}$.

Redit Status Comprehensive Evaluation. Fuzzy matrix R rating and weighting set W, can be calculated weighted composite membership vector P. The formula is: 


$$
P=W \times\left|R_{i}\right|=\left(W_{1}, W_{2}, \ldots, W_{m}\right) \times\left|\begin{array}{cccc}
r_{11} & r_{12} & \ldots & r_{15} \\
r_{21} & r_{22} & \ldots & r_{25} \\
\ldots & \ldots & \ldots & \ldots \\
r_{m 1} & r_{m 2} & \ldots & r_{m 5}
\end{array}\right|
$$

And the introduction of fractional set $F=(100,80,60,40,20) \mathrm{T}$, to obtain the final results of fuzzy comprehensive evaluation value of $\mathrm{Z}$ :

$$
Z=P \cdot F
$$

Fuzzy comprehensive evaluation based on the value of $Z$ scores to determine the individual's credit rating. 100-80 score in credit conditions is divided between excellent, as good 80-60 minutes between for 60-40 minutes in between, as the difference between $40-20$ points, between points $20-0$ very bad. Individual credit risk assessment results correspond respectively to low, low, in general, higher, higher.

\section{Conclusions}

This study was conducted in the mortgage, car loan, venture capital and other personal demand, bank personal credit review system for continuous improvement, individual credit risk assessment system need to be improved in the context of the proposed. In this paper, personal credit evaluation, evaluation model, index weights has done a detailed argument. Given the current situation of personal credit and financing difficulties, the establishment of personal credit evaluation system includes four basic family, family finances, credit and credit behavior; by Fuzzy AHP Comprehensive Evaluation Method to improve the use of AHP and group decision making Delphi combination to determine the weight of index, Delphi method can guarantee the authority to determine the index weight, group decision making AHP judgment result reflects the will of the group's influence to avoid the one-sidedness of expert judgment; quantitative and qualitative indicators were used expert scoring method and interpolation method to get the membership of each metric. The improved fuzzy AHP comprehensive evaluation method to improve the personal credit evaluation system, clear weight concrete method of determining membership, so that individual credit risk rating method is more scientific and reasonable.

\section{References}

[1] Pang Lei. AHP- Fuzzy Comprehensive Evaluation Method in the SME Rating [J]. Chinese Prices. 2015, 4, (69-71).

[2] Zhao Xiaodong, Zheng Tao. Based on Personal Credit Rating Index System Model A FUZZY AHP Evaluation Method [J]. Quantitative And Technical Economics Research . 2003 No. 6 (97-100).

[3] Zhang Xueli, Zhu Xin, Yu Lixin. Research Discriminant Analysis of Commercial Bank Personal Credit Risk Assessment Model [J]. Industrial Technology \& Economy. 2011, 10, (133-138).

[4] Ye Weichun. Credit Rating Theory and Practice. Shanghai People's Publishing House [M]. 2011 9, (149-150).

[5] Wang Liang, Jiang Binglin. AHP Comprehensive Evaluation of Commercial Bank Personal Credit Fuzzy [J].Technology And Management. 2007, 4, (45-46).

[6] Mao Junquan. Personal Credit Assessment Fuzzy Comprehensive Evaluation Model [J]. Enterprise Economy. 20086 (63-65).

[7] Kruppa, Jochen; Schwarz, Alexandra; Arminger, Gerhard; Ziegler, Andreas, Consumer Credit Risk: Individual Probability Estimates Using Machine Learning, Expert Systems with Applications volume 40, Issue 13, 1 October 2013, Pages 5125-5131. 